\title{
Do the DMO and the Tourists Deliver the Similar Image? Research on Representation of the Health Destination Image Based on UGC and the Theory of Discourse Power: A Case Study of Bama, China
}

\author{
Xueying Huang ${ }^{1}$, Yuanjun Han ${ }^{2, *}$, Qiuli Meng ${ }^{3}$, Xiaoxia Zeng ${ }^{1, *(\mathbb{D}}$ and Huilan Liao ${ }^{1}$ \\ 1 College of Business Administration, Guangxi University of Finance and Economics, Nanning 530003, China; \\ xyhuang@gxufe.edu.cn (X.H.); liaohlms@gxufe.edu.cn (H.L.) \\ 2 China Tourism Academy, Beijing 100005, China \\ 3 School of Management, Guangxi University for Nationalities, Nanning 530006, China; mq10814@126.com \\ * Correspondence: yjhan@cnta.gov.cn (Y.H.); zengxx@gxufe.edu.cn (X.Z.); Tel.:+86-136-8102-1537 (Y.H.); \\ +86-182-0771-2921 (X.Z.)
}

check for

updates

Citation: Huang, X.; Han, Y.; Meng, Q.; Zeng, X.; Liao, H. Do the DMO and the Tourists Deliver the Similar Image? Research on Representation of the Health Destination Image Based on UGC and the Theory of Discourse Power: A Case Study of Bama, China. Sustainability 2022, 14 953. https://doi.org/10.3390/ su14020953

Academic Editor: Colin Michael Hall

Received: 8 December 2021

Accepted: 11 January 2022

Published: 14 January 2022

Publisher's Note: MDPI stays neutral with regard to jurisdictional claims in published maps and institutional affiliations.

Copyright: (C) 2022 by the authors. Licensee MDPI, Basel, Switzerland. This article is an open access article distributed under the terms and conditions of the Creative Commons Attribution (CC BY) license (https:// creativecommons.org/licenses/by/ $4.0 /)$.

\begin{abstract}
Even though destination image is an important expression of discovering the local landscapes and place significance, the construction and measurement of destination image neglect the place component. This research explores the image of health destinations, as well as its representation mechanism, combining the triadic structure of tourism image proposed by Marine-Roig et al. with the theory of discourse power put forward by Michel Foucault, taking Bama, Guangxi as a case. In addition, this paper uses the IPA matrix to visually unveil the pronounced gap between the projected image by Destination Management Organizations (DMOs) and the perceived image of tourists and suggests strategies that DMOs should adopt in the different dimensions.
\end{abstract}

Keywords: health destination; UGC; TDI representation; discourse power; Bama; China

\section{Introduction}

With the rapid development of Internet technology and mobile communication technique, human society has already entered a highly shared information era. User-generated content (UGC), including narrative text and photograph, becomes a major platform for potential tourists to collect travel information, and it is also an important channel for destination image perceptions, travel decision-making and tourist behavior tracking [1]. The online narrative texts and photographs posted by tourists are crucial for cultural and spatial representation of tourist destination as well, but the studies UGC-based on this field are insufficient. Most previous text-and-photograph-based research on representation of tourist destinations has prevailingly adopted human analysis of content or semantics with limited sample sizes [2-4]. For analysis on massive volumes of UGC including texts and photographs, a more automated analysis approach is essential to improve efficiency and data objectivity. At the same time, the previous studies pay more attention to the tourist-side issues based on UGC, such as destination image communication and tourist experience. Whereas the DMO-side, who's an important stakeholder for spatial production and image construction in destination, is fewer and needs to be strengthened, as well as the comparative research between the two sides [5,6]. By conducting a comparison study on the UGC-based representation of travel destination from the two perspectives of DMO and tourist, which is one of the theoretical contributions this study might make.

Due to the differentiated core interests between the stakeholders, it causes us to reflect on the following questions: Who is the subject of cultural and spatial representation in tourist destinations? Who holds the power of representation? How do these power subjects impact the representation? With the guidance of these questions, we introduce the theory 
of discourse power put forward by Michel Foucault into the UGC-based comparison research on the representation of tourist destination. For now, it is relatively insufficient for the present research to focus on the representation of tourist destination from the discourse power perspective. Therefore, this study aims to figure out how UGC-based health destinations are represented in the light of discourse power theory. Balshaw and Kennedy [2] believe that a place is the result of representation, and it is controlled by the choice of human society to figure out how representation is conducted. The reason why a certain place becomes a tourist destination is actually a historical choice, and also depends on concentrated embodiment of will by a certain social class and its representatives. Foucault [7] believes that the will of the above-mentioned dominant class is expressed through "discourse", which hides complex power relations and embodies the will of a specific social power. While Lefebvre [8] believes that there is a false "epistemological priority" overriding the reality of social space in the representation of real images or texts, focusing on how space conceals power relations, and characterizing the urban structure that brings us a partial, illusory, and temporary visible space. Based on the above research, Danping Liu [9] believes that the process by which a tourist destination is represented is an act of cultural reproduction. In this process, the local government, tourism developers, residents, and tourists jointly reconstruct the original place and form "the unreal world". Similarly, regarding the tourist destination image (TDI), this article focuses on two subjects of power implementation: the DMO and the tourist. However, according to Foucault's discourse power theory, this article pays more attention to how the power of the DMO and tourists operates in a comparison research framework. This might be the other theoretical advancement, furtherly.

The comparative research between two power subjects may lead to a practical problem, that is, the representation content of tourist destination conveyed by tourists and DMOs are likely to be inconsistent, and the same goes for destination image. The research conclusions have very important practical significance in terms of the improvement on destination marketing for the DMO. The research findings suggest an improvement direction for DMO to reshape the overall image of the destination. At the same time, the sentiment analysis of tourists on the representation of travel destinations can point out the directions for the promotion and development of health destinations and spatial reconstruction.

This article mainly focuses on the image representation of health destination based on Michel Foucault's discourse power theory. We conduct a case study of Bama, China, based on UGC texts and photos released by both DMO and tourists, to unveil the projected and perceived TDI of Bama, disclose the TDI measurement dimensions of health destination with three-level coding of the Grounded Theory Approach, and extract the spatial/place, cognitive, and affective components of image. In this exploratory study, it helps to construct an integrated system of TDI, using pictorial data as an effective supplement to text data. The data were obtained from the OTA including Ctrip, Mafengwo, et, al., the official MicroBlog of Bama tourism administration department on Sina Open Platform and its WeChat Official Account. The UGC material such travelogue and photographs about Bama were included in data collection. Semantic, sentimental and picturesque analysis will be used to describe the image of health destinations. Additionally, we try to uncover the gap between DMO and tourists in TDI building of Bama on basis of the IPA model.

The current research on destination tourism image construction based on tourist text or image big data is increasing, and the analytical framework constructed for tourism image research mainly includes cognitive image, affective image and total image. However, not just in a perceived image but the projected image also consists of a cognitive and affective evaluation of DMO [10]. Noting the above problem, Deng and Li [4] implement a machine learning-based model to assist DMOs with photo content selection using UGC images as a data source. Stepchenkova et al. [11] conducted a comparative study using data from images published by DMOs and tourists, and address the pronounced gap between projected and perceived images. Unlike the above two, this paper unifies DMO projected image and tourists perceived image into the construction of destination image measurement 
scales, and the research object is the image construction of a specific type of destination which is health tourism destination. Taking Bama, Guangxi as a case study, we use the text and images released by DMOs and tourists as data sources, adopt exploratory research methods such as image analysis, text analysis and IPA model to explore the representation and construction process of DMOs and tourists' image of health tourism in Bama. Then, taking the formation mechanism of its wellness tourism image and the representational power characteristics of the natives, DMO and tourist-related operators, and tourists in its formation process were analyzed. Moreover, based on the triadic structure of tourism image (spatial, cognitive and affective image) proposed by Marine-Roig et al. and combined with the theory of discourse power put forward by Michel Foucault, a comprehensive analysis framework of the image of health tourism is formed. Finally, the IPA construction matrix is used to compare the differences between the projected tourism image of DMOs and the perceived image of tourists under the above analysis framework, and to suggest strategies to be adopted by DMOs in the different elemental dimensions.

\section{Literature Review}

\subsection{The Projected Image and Perceived Image}

Classical destination image theory divides destination images into a projected image on the supply side and a perceived image on the demand side, depending on the subject $[12,13]$. In terms of construct order and cognitive hierarchy, destination images are widely considered to be divided into cognitive and affective aspects, and are thought to follow a sublimation process from cognitive image to affective image $[14,15]$.

After the tourism image of tourist destination is going into the market, scholars' study on whether the "projected image" is consistent with the tourist's "perceived image" from different perspectives, and then examine it. Marine-Roig et al. [16] used the composition analysis method to compare the "projected image" of Catalonia tourism administration files and tourism guide with UGC on the internet. Athena [17] takes Eastern Taiwan as an example to explore the differences between "perceived image" and "projected image" by using visual content and visual analysis of image data, text content analysis and other methods. The author thinks that the National Tourism Organization is the media of "projecting image", and compares the "projected image" with UGC on the internet. Stepchenkova \& Zhan [6] takes Peru as an example, and through collecting and screening the propaganda content of DMO website and UGC on the internet to visualize the image, constructing Peru's map of "projected image" and "perceived image" and its geographical distribution map, and makes a comparative analysis of the differences between them. Other scholars use the social semiotics analysis method to deconstruct the tourist manual and guide manual and the tourist photos and texts representing the tourists' perceived image. The online photos and characters of tourists are self-expression of the personal tourism experience and play a supplementary role in "projected image".

\subsection{The TDI in the Context of UGC}

\subsubsection{UGC Text-Induced TDI}

The dissemination of tourism destination terrain image is of great significance. Scholars use content analysis method to study the tourism destination terrain image based on the network text. The mining of network resources plays an important role in the grasp of tourism image of tourism destination. Some scholars study the image of tourist destination through text. The main way of surveying tourism destination topography is a questionnaire survey [18], while some studies analyze the self-contained materials of tourists by text analysis, examines the basic elements of place perception and the inter-elements results, which plays a complementary role in the theory of tourism perception [19].

Studies suggest that the dissemination effect of tourism image will be different due to the different tourism market [20]. Additionally, the research materials are the publicity information published by tourism websites to explore the image of tourism destination online tourism [21]. Some scholars discuss the formation process of tourism brand, analyze 
the development status, tourism characteristics and brand building of tourist destination in different periods, and explore the image perception characteristics and image structure of tourist destination, by use of the publicity photos on the official website as the research materials for projected image and the tourist online travel photos as the research materials of perceived image [22].

\subsubsection{UGC Photo-Induced TDI}

In the context of new media, tourists can share their tourism experiences in the form of pictures through the network platform, and UGC is widely used as the data source of tourism research; given the importance of UGC to tourists' information-seeking, travel decision-making and other behaviors. In recent years, scholars have studied the use of UGC by tourists and the process of UGC's influence in tourists' planning behavior [23]. Moreover, due to the intuitiveness of the information transmitted, the picture becomes one of the main information carriers in UGC and an important medium for tourists to perceive the tourist destination terrain image [24]. Through the image survey of the destination topography, the image content is classified and studied, and the tourists' preference for the tourist destination is obtained through the analysis of the picture content, which has a high reference value for the transmission and construction of the tourist destination image [4,25].

It is found that UGC images are based on the perception of the destination image from the tourist's perspective and that there are differences between the destination image conveyed by the DMO $[5,6,16]$. Moreover, UGC images can arouse trust and resonance of potential tourists more than those of DMO [26], which has become one of the main ways to spread the target terrain image. In the aspect of image analysis, content analysis and symbolic analysis are mainly used; however, it is mainly content analysis $[4,6,10,15,25,27,28]$. Based on cognitive psychology, computing science and other disciplines, scholars have explored cognitive factors of destination perceived image, positive or negative emotional factors and overall perceived image of tourist destination by virtue of various new data mainly based on UGC data, explored cognitive image, emotional image and overall image of tourist destination, and constructed many target terrain image measurement models [25].

In recent years, in a context dominated by online UGC, the traditional projected image of a destination has been generalized to an online image, which is influenced by the joint action of the DMO and the content posted by tourists. Then, the first question we need to answer is whether the TDI theoretical framework, which is built based on the UGC delivered by DMOs and tourists, improves the knowledge gap, compared to previous studies.

\subsection{The Discourse Power and TDI}

"Discourse" is a kind of relationship construction, and it is an important activity under some context or mechanism. Discourse itself is power; discourse, knowledge and power are interlinked and mutually constrained. Knowledge generates power, power and knowledge regulate and produce discourse, and discourse further enforces power by producing and maintaining knowledge [7]. Tourism discourse has become a marketing content and interpretation method for constructing the image of tourism destinations, and scholars have adopted a multimodal approach based on semiotic and visual consumption perspectives, using textual content and symbolic representations to present and construct [29].

Tourism discourse is not only a description of the real world, but also a reflection of social power mechanisms. The image of a tourism destination is presented, represented or constructed through discourse, which in turn is influenced by historical contexts, power relations, social structures, ideologies, public memory and other factors [30]. In modern or post-modern societies, it is not efficient and convenient transport that gets the traveller to the country or city of destination, but the textual and visual symbols that populate the website. [31]. As a traditional information "center", DMO has been gradually weakened [32]. Destination image communication has changed from being dominated by DMOs to being co-led by UGC and DMOs, with focused UGC content becoming the key to destination 
marketing [33]. Then, we need to figure out who are the stakeholders and how they contribute to the TDI construction of health destination. Therefore, it is important to work out the process and mechanism of TDI construction, and it is the second question we need to answer.

It is testified in previous studies that there is a gap on the structure and dimensions of TDI representation between DMOs and tourists [5,6]. However, the theoretical framework of TDI constructed in this study is different from previous studies, as wellness of the health destinations have their characteristics, in this case Bama, China, where the elderly, especially centenarians are unique components of the local people which is different from the indigenous of other tourist destinations. In addition, there is a branch of sojourners who live for the purpose of health and wellness in Bama. Therefore, the TDI represented by DMOs and tourists might show a different pattern, and we need to figure out what kinds of differences on the TDI representation of Bama exist between the DMOs and the tourists. This is the third question to be addressed in this study.

\section{Study Methods}

\subsection{Destination Choice}

This paper conducts a comparative study on the projected and perceived image of health tourism destination. The selected research object is Bama Yao Autonomous County in Guangxi Zhuang Autonomous Region, which has 103 administrative villages in 3 towns and 7 townships, inhabited by 12 ethnic groups, including Yao, Zhuang, Han, Miao, Maonan, Mulao, Hui and Shui, with a total population of 299,100 people and 260,000 ethnic minorities, accounting for $86.9 \%$ of the total population, including 53,000 Yao people. With a good ecological environment and a suitable climate, Bama has a vegetation cover of over $70 \%$. Of the population, there are on average 30.98 long-lived people over 100-years-old of age per 100,000 people, listing it in the fifth longest-lived town in the world, and it is also known as an international health resort. One of the authors has practical experience of working in the tourism sector in Bama and understands the history and current status of its tourism development and marketing, which is why Bama was chosen as the subject of this study. Prior to the conscious promotion of tourism by the local tourism authorities, Bama was known to the outside world mainly through "word of mouth". The exaggerated publicity of the Bama longevity phenomenon on the internet has led to an influx of the sojourner (titled as "migratory birders") and tourists, impacted the ecological environment while becoming more commercialized, and the native lifestyle is changing in a subtle way. Bama has become a place for sojourners to recuperate, due to the local tourism authorities' preference for "longevity" and "health" selling points. The user generated contents of travel websites such as Mafengwo and Ctrip provide more convincing reference information for potential travelers. Our tourism image analysis framework was developed from the UGC text and image contents by travelers, combined with the DMO's posted on Weibo and WeChat public websites.

\subsection{Data Collection}

The data types for this study include text and pictures. As a comparative study of the projected image of DMOs and the perceived image of travelers needs to be conducted, the data consisted of two main parts, one consisting of online travelogues and photos posted by travelers, and the other consisting of text and pictures posted by DMOs for destination promotion purposes. The sources of travelogues and pictures by tourists include Ctrip, Mafengwo, Qunar, Tuniu, and Lvmama. We excluded platforms such as Dianping, Meituan and Baidu, because these platforms are abundant in reviews of single tourist products such as scenic spots and hotels, and lack comments on the overall perception of tourist destinations; Baidu Travel has ceased its services since 30 June 2019. The sources of text and image data released by DMO include Weibo and WeChat. In 2016, Bama Tourism Bureau started to set up the official Sina Weibo homepage and WeChat official account, so all the data from 1 January 2016 to 31 December 2020 were downloaded. For the UGC 
data of travelers, more than 600 travelogues related to Bama were collected, and after manual screening and elimination, a total of 229 articles were left, with a total Chinese word count of almost 700,000 words and 793 pictures; for the UGC data of DMO, a total of 328 articles were collected, and 249 articles were obtained after eliminating duplicate data, with Chinese words count of over 80,000 words and 701 pictures.

\subsection{Methods}

In the context dominated by online UGC, the projected image of traditional destination is generalized into an online image, which is jointly acted upon and influenced by the DMO and the content posted by tourists [15]. Based on the content analysis of text and picture, this article builds a systematic measurement scale including spatial/place, cognitive and affective dimensions, and reflecting the regional characteristics of Bama, for cognitive image of health destination, as well as affective image. It also explores the process of TDI representation of Bama's health tourism based on Michel Foucault's theory of discourse power. Then, a comparative study of DMO's projected tourism image and tourists perceived image is conducted with the help of semantic comparison of projected-perceived images and IPA model, in order to provide reference for the improvement of DMO's tourism image projection strategies.

\subsubsection{Text Analysis}

The content analysis method and ROST software were used to obtain a list of highfrequency terms for projected and perceived images of tourism, using data from DMO and tourists' individually. Through literature review and sample verification, the image perception elements summarized in the literature and the high frequency image perception elements extracted based on UGC data are matched to ensure that the constructed TDI element system fits the characteristics of the research object. In order to ensure the scientificity of the thesaurus, manual reading was adopted to amend and supplement the ROST software's thesaurus, thus constructing a more complete image measurement scale of Bama's TDI. Specifically, for the coding method of keywords, this study adopts an exploratory research approach that includes open coding, axis coding and selective coding.

\subsubsection{Picture Analysis}

Referring to Stepchenkova \& Zhan [6], Deng \& Li [4], the picture-based TDI classification method that is DeepSentiBank is used to parse the pictures, and each image is analyzed to obtain 2089 pairs of adjectives and nouns (ANP). In order to highlight the key landscape, only the first 10 ANPs were retained for each image, and the nouns and their word frequencies were stripped out, followed by manual clustering to determine the cognitive dimensions, classify the photos into image attributes, and sort out the keywords contained in each classification dimension. An example of picture analysis is in Figure 1. The example picture is a landscape picture of Ming River, Bama. This picture only lists the top 5 ANP data results. The larger the ANP value, the higher the ranking and the stronger the relevance to the image content [27].

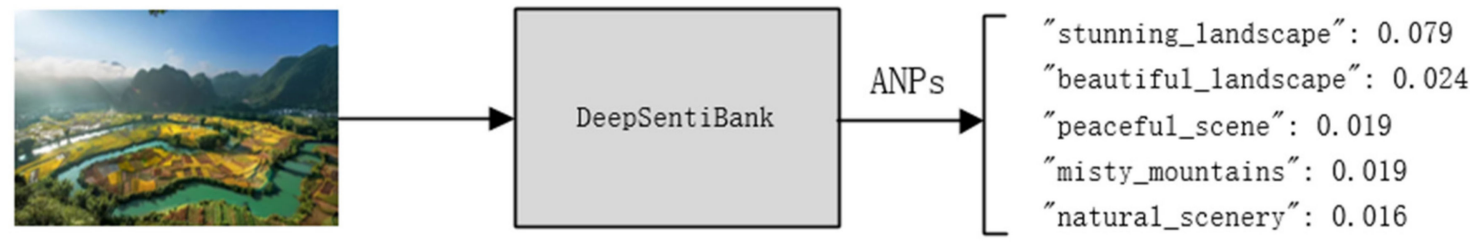

Figure 1. Example of photos processed and analyzed by DeepSentiBank.

Among them, the nouns obtained from the image analysis are descriptions of the content of the images, which are objective expressions of the regional characteristics and cognitive image of the tourist destination; while the adjectives reflect the photographer's 
emotional inclination towards a specific object, which can be regarded as a reflection of the emotional image. Emotional images are predominantly textual, as emotions are usually expressed by words. Some images can express emotions, but most of them are neutral displays. Moreover, from the photos currently available, tourists prefer to capture scenes and things that express positive and neutral emotions, and there are few images that reflect negative emotions. With regard to the analysis of emotional images, this paper focuses on textual analysis. The analysis of the content of the images can complement the composition of the elements of destination image and further validate the theory of destination image developed through the textual analysis.

\subsubsection{Emotion Analysis}

In general, photos from social networks contain abundant descriptive information in the form of metadata, which is highly significant in content analysis [28]. Meanwhile, photos on social networks usually allow viewers to leave comments, which are ideal material for sentiment analysis [4]. Therefore, regarding the sentiment analysis of Bama's tourism image, we combined the high-frequency words of text and pictures to implement this research. Since the text obtained in this study is Chinese, we refer to Meng et al. [10] method of constructing tourists' sentiment lexicon, based on HowNet released by CNKI sentiment dictionary, for sentiment classification and analysis. For high-frequency words that cannot be matched with the sentiment dictionary, manual classification is carried out to (1) construct the sentiment vocabulary of this study, (2) use Python snowNLP to write codes to make judgement for sentiment orientation of each travelogue, and finally (3) obtain the overall affective image of destination. Then, according to the high-frequency words, it explores the tourist's perception factors of Bama TDI from both positive and negative aspects.

\subsubsection{IPA Model}

IPA (Importance Performance Analysis) model was introduced into the field of tourism research by Choi et al. [21] to show the state of elements of tourism destination image in the importance and performance matrix. It is used to directly evaluate the difference between perceived and projected tourism images. In this study, the high-frequency words analyzed from DMO publicity text are important elements recognized by DMO in the perception of TDI, which is the importance axis in the IPA model. The high-frequency words analyzed from the texts of online travelogues reflect the element of tourists' perception of TDI, which is the performance axis in the IPA model. To sum up, we present the ratio of the frequency of keywords parsed in the travelogue text to the number of acquired travelogues for each element on the above two axes in the IPA matrix to visualize the difference between the important factors and the actual perception of tourism image perception, thus providing a basis for tourism destination image enhancement. The specific calculation method is to use the probability of occurrence of each measurement scale in DMO text or image parsing keywords as an indicator of its importance. In the screening process, the presence of the factor was recorded as 1 and the absence of the factor was recorded as 0 . Referring to the methods of Meng et al. [10] and Shi et al. [5], the formula is as follows:

$$
\begin{gathered}
I_{i}=f_{i} / N \\
P_{i}=m_{i} / M
\end{gathered}
$$

$I_{i}$ and $P_{i}$ represent Bama's perceived importance of travel image and actual performance scores, respectively. In Equation (1), $f_{i}$ represents the frequency of the $i$ factor precipitated from the texts or pictures released by tourists, and $N$ represents the total number of articles or pictures obtained from the travelogue texts released by tourists. In Equation (2), $m_{i}$ represents the frequency of $i$ factor precipitated from texts or pictures published by $\mathrm{DMO}$, and $M$ represents the total number of articles or pictures obtained from travelogues published by DMO. 


\section{Presentation and Process for TDI of Health Destination: UGC-Based Analysis on Bama}

\subsection{Results of Text Analysis}

Not just in a perceived image but the projected image also, consists of a cognitive and affective evaluation of DMO [10]. Therefore, through UGC keyword extraction and coding by tourists and DMOs, the categories of health destination TDI for Bama was constructed.

\subsubsection{High-Frequency Words Extraction}

Based on the method described above, keywords were extracted and conceptualized for Bama-related online travelogues and DMO publicity texts, an example of which is shown in Table 1.

Table 1. Example of open coding.

\begin{tabular}{|c|c|c|c|}
\hline No. & Text & $\begin{array}{l}\text { Semantic and } \\
\text { Concept Extract }\end{array}$ & Conceptualization \\
\hline 1 & $\begin{array}{l}\text { Baimo Cave is right next to where we } \\
\text { live. It is said that content of negative } \\
\text { oxide ions is surprisingly high in the } \\
\text { cave. Although the scenic area is closed } \\
\text { at this time, there are still a crowd of } \\
\text { people, such as sojourners and travelers, } \\
\text { standing at the entrance of the cave to } \\
\text { inhale the fresh air. }\end{array}$ & $\begin{array}{c}\text { Baimo Cave } \\
\text { Air/negative oxide } \\
\text { ions } \\
\text { Scenic area } \\
\text { Sojourners }\end{array}$ & $\begin{array}{l}\text { Tourist attractions } \\
\text { Longevity, health and } \\
\text { resources } \\
\text { Health and } \\
\text { recreational areas } \\
\text { People }\end{array}$ \\
\hline
\end{tabular}

Table 2 lists top 50 high-frequency words in UGC related to Bama by tourists and DMO. The top 50 keywords characterizing the tourist image perceived by tourists and the tourism image projected by DMO have 19 repetitive words, with an overlap of 38\%. The No.1 high-frequency word of both visitor perception and DMO promotion is "Bama", indicating that the overall image of Bama as a health destination has been identified.

\subsubsection{Dimension Analysis}

Open coding. The keywords of Table 2 (related words mentioned in the travelogue about the perception of destination, such as Baimo Cave and negative oxygen ions) were collated and named conceptually, and summarized with reference to the categories and classification principles of cognitive factors in the literature review. The 18 representational categories for tourist perceived TDI were extracted and summarized is "geographical location", "health and recreational areas", "access", "transportation", "karst topography", "longevity, health and natural resources", "longevity, health and cultural resources", " climate", "landscapes", "ethnic minority culture", "image brand/label", "people", "tourist attractions", "tourist infrastructure", "tourist service", "tourist activities", "imagery and experience assessment". Based on the top 50 keywords in DMO data, the concept of "social life and atmosphere" is extracted. To further discover new concepts, we extend the range of keywords extracted from the UGC by tourists to the top 100 and 150, respectively, and the theory reached saturation because no new theoretical coding appears.

Axial coding. The names of the split concepts are clustered and analyzed to establish links between the different categories, grouping them one by one to form a potential skeleton. After the categorization and logical sorting of the categories, the paper delineates eight categories including "places", "accessibility/supporting infrastructure", "natural topography", "natural and social environment", "health destination characteristics/environment", "tourist characteristics/environment", "imagery" and "experience assessment". 
Table 2. High-frequency words in user generated content related Bama by tourists and DMO (top 50).

\begin{tabular}{|c|c|c|c|c|c|c|c|c|c|c|c|}
\hline \multirow[b]{2}{*}{ No. } & \multicolumn{4}{|c|}{ UGC by Tourist } & \multirow[b]{2}{*}{ Frequency } & \multirow[b]{2}{*}{ No. } & \multirow[b]{2}{*}{ Words } & \multicolumn{3}{|c|}{ UGC by DMO } & \multirow[b]{2}{*}{ Frequency } \\
\hline & Words & Frequency & No. & Words & & & & Frequency & No. & Words & \\
\hline 1 & Bama & 2034 & 26 & skylight & 215 & 1 & Bama & 518 & 26 & Bird Rock & 38 \\
\hline 2 & landscape & 1155 & 27 & sunlight & 194 & 2 & travel & 410 & 27 & show & 37 \\
\hline 3 & karst cave & 1129 & 28 & sojourners & 193 & 3 & scenic spot & 392 & 28 & discount & 37 \\
\hline 4 & Baimo Cave & 825 & 29 & stalactite & 192 & 4 & tourist & 247 & 29 & reception & 37 \\
\hline 5 & tickets & 908 & 30 & tour guide & 192 & 5 & activity & 174 & 30 & Longevity Island & 34 \\
\hline 6 & hotel & 892 & 31 & geomagnetism & 187 & 6 & game & 110 & 31 & Free & 33 \\
\hline 7 & water & 855 & 32 & $\begin{array}{l}\text { mountains and } \\
\text { rivers }\end{array}$ & 183 & 7 & longevity & 106 & 32 & museum & 30 \\
\hline 8 & longevity & 604 & 33 & health & 181 & 8 & $\begin{array}{l}\text { health } \\
\text { Yao }\end{array}$ & 95 & 33 & Ci Fu Lake & 30 \\
\hline 9 & Longevity Village & 561 & 34 & nature & 178 & 9 & $\begin{array}{l}\text { Autonomous } \\
\text { County }\end{array}$ & 85 & 34 & Panyang River & 30 \\
\hline 10 & Panyang River & 396 & 35 & gourmet & 174 & 10 & international & 79 & 35 & nationality & 29 \\
\hline 11 & $\begin{array}{l}\text { health } \\
\text { preservation }\end{array}$ & 443 & 36 & karst river & 169 & 11 & $\begin{array}{c}\text { health } \\
\text { preservation }\end{array}$ & 79 & 36 & building & 29 \\
\hline 12 & feeling & 492 & 37 & idyllic & 169 & 12 & travel agency & 77 & 37 & Cave Paradise & 29 \\
\hline 13 & Land of Longevity & 386 & 38 & bus station & 168 & 13 & industry & 68 & 38 & ecology & 28 \\
\hline 15 & Crystal Palace & 321 & 40 & minority & 165 & 15 & Crystal Palace & 60 & 40 & intangible heritage & 25 \\
\hline 16 & Bird Rock & 298 & 41 & rural & 158 & 16 & Baimo Cave & 60 & 41 & folk song & 24 \\
\hline 17 & highway & 380 & 42 & show & 157 & 17 & rural & 53 & 42 & landscape & 24 \\
\hline 18 & tour & 336 & 43 & supernatural & 150 & 18 & service & 47 & 43 & Zhuang nationality & 24 \\
\hline 19 & air & 295 & 44 & Minghe River & 145 & 19 & experience & 44 & 44 & laid back & 24 \\
\hline 20 & centenarian & 276 & 45 & Yao Village & 145 & 20 & Hechi & 43 & 45 & tickets & 23 \\
\hline 21 & cave entrance & 266 & 46 & climate & 145 & 21 & $\begin{array}{c}\text { benevolence and } \\
\text { longevity }\end{array}$ & 43 & 46 & folklore & 22 \\
\hline 22 & building & 244 & 47 & $\begin{array}{l}\text { Jiazhuan } \\
\text { Township }\end{array}$ & 141 & 22 & team & 41 & 47 & longevity culture & 21 \\
\hline 23 & doline & 231 & 48 & Ci Fu Lake & 135 & 23 & tour & 41 & 48 & $\begin{array}{l}\text { replenish food and } \\
\text { increase longevity }\end{array}$ & 21 \\
\hline 24 & free & 231 & 49 & natives & 130 & 24 & hotel & 38 & 49 & karst cave & 21 \\
\hline 25 & $\begin{array}{c}\text { negative oxygen } \\
\text { ions }\end{array}$ & 225 & 50 & restaurant & 130 & 25 & product & 29 & 50 & $\begin{array}{l}\text { March 3rd in lunar } \\
\text { calendar }\end{array}$ & 20 \\
\hline
\end{tabular}


Selective coding. Further linkages between the above categories were established through twice coded category extractions and in-depth examination and analysis, and then incorporate the eight categories into three core dimensions which are spatial/place, cognitive and affective components, formulating the TDI measurement scales of health destination for Bama.

As to the emotional tendency of tourists' travelogues towards Bama's TDI, according to the aforementioned sentiment analysis method, 17 negative travelogues are obtained, 94\% of tourists' travelogues are positive in overall evaluation of Bama TDI, while the negative evaluation accounted for about $6 \%$. We also mined, summarized and analyzed the highfrequency words, among which is in the top 50 words, the words "health preservation" and "Land of Longevity" express the attributes and identification of Bama as a health destination. In order to better construct the TDI of the health destination, the top 150 high frequency words in the travelogue text were summarized and analyzed, and the "imagery" dimension was extracted from "Xanadu/Arcadia", "poetic imagery" and "fairyland". The "experience assessment" dimension was extracted from "supernatural", "unique", "appreciation", "taking a picture", "holly land", "spectacular", "worthy", "mysterious", et al. In addition, the "future behavior" dimension is extracted from the words "return", "linger", "recommend" which express positive feelings and "won't go back" which express negative feelings. One of the travelogues clearly expresses "The place is a nice place, but everywhere is being built dirty and messy, so I won't go back!" (Netizen Guiniangshuyu, from Mafengwo).

\subsection{Results of Picture Analysis}

\subsubsection{Result of High-frequency Words from Picture-parsing}

In order to further test whether the theory is saturated, pictures from the travelogues were subsequently crawled, parsed and theoretically coded to further complement and validate the image category construction for TDI of Bama as a health destination. In this paper, the content of pictures posted by travelers and DMO were analyzed statistically to obtain high frequency nouns and adjectives, respectively (see Table 3).

Table 3. The high-frequency words of Bama related pictures content by tourists and DMO (top 30).

\begin{tabular}{|c|c|c|c|c|c|c|c|c|c|c|c|}
\hline \multirow[b]{2}{*}{ No. } & \multicolumn{4}{|c|}{ Photos by Tourist } & \multirow[b]{2}{*}{ Frequency } & \multirow[b]{2}{*}{ No. } & \multirow[b]{2}{*}{ Adjectives } & \multicolumn{3}{|c|}{ Photos by DMO } & \multirow[b]{2}{*}{ Frequency } \\
\hline & Adjectives & Frequency & No. & Nouns & & & & Frequency & No. & Nouns & \\
\hline 1 & misty & 375 & 1 & mountains & 304 & 1 & traditional & 225 & 1 & food & 250 \\
\hline 2 & ancient & 327 & 2 & street & 269 & 2 & healthy & 218 & 2 & adventure & 166 \\
\hline 3 & natural & 304 & 3 & city & 250 & 3 & super & 207 & 3 & city & 139 \\
\hline 4 & famous & 225 & 4 & food & 227 & 4 & outdoor & 168 & 4 & scenery & 124 \\
\hline 5 & stunning & 217 & 5 & house & 216 & 5 & great & 149 & 5 & cars & 123 \\
\hline 6 & peaceful & 215 & 6 & view & 213 & 6 & horizontal & 139 & 6 & kids & 215 \\
\hline 7 & magnificent & 190 & 7 & lake & 177 & 7 & famous & 136 & 7 & crowd & 115 \\
\hline 8 & traditional & 181 & 8 & garden & 175 & 8 & successful & 133 & 8 & water & 112 \\
\hline 9 & cloudy & 178 & 9 & river & 175 & 9 & natural & 132 & 9 & girls & 109 \\
\hline 10 & great & 137 & 10 & landscape & 171 & 10 & amazing & 131 & 10 & sign & 104 \\
\hline 11 & quiet & 134 & 11 & building & 160 & 11 & holy & 117 & 11 & business & 98 \\
\hline 12 & calm & 130 & 12 & architecture & 136 & 12 & young & 101 & 12 & street & 95 \\
\hline 13 & tranquil & 126 & 13 & rain & 119 & 13 & funny & 95 & 13 & team & 85 \\
\hline 14 & outdoor & 123 & 14 & scene & 114 & 14 & happy & 93 & 14 & lake & 81 \\
\hline 15 & nice & 118 & 15 & castle & 110 & 15 & safe & 90 & 15 & night & 80 \\
\hline 16 & rainy & 111 & 16 & bridge & 107 & 16 & favorite & 87 & 16 & landscape & 77 \\
\hline 17 & lovely & 105 & 17 & road & 104 & 17 & ancient & 80 & 17 & dress & 74 \\
\hline 18 & beautiful & 103 & 18 & park & 102 & 18 & nice & 77 & 18 & dance & 71 \\
\hline 19 & scenic & 90 & 19 & valley & 99 & 19 & magnificent & 73 & 19 & weight & 62 \\
\hline 20 & expensive & 82 & 20 & water & 95 & 20 & stunning & 73 & 20 & race & 54 \\
\hline 21 & gorgeous & 77 & 21 & scenery & 91 & 21 & fresh & 71 & 21 & lights & 54 \\
\hline 22 & hot & 71 & 22 & hills & 90 & 22 & expensive & 70 & 22 & river & 51 \\
\hline 23 & busy & 70 & 23 & pool & 88 & 23 & golden & 64 & 23 & places & 48 \\
\hline 24 & serene & 69 & 24 & hotel & 77 & 24 & lost & 62 & 24 & book & 48 \\
\hline 25 & outdoor & 65 & 25 & home & 64 & 25 & busy & 62 & 25 & training & 47 \\
\hline 26 & charming & 61 & 26 & morning & 61 & 26 & excited & 58 & 26 & heritage & 39 \\
\hline 27 & strange & 50 & 27 & places & 55 & 27 & bright & 57 & 27 & festival & 38 \\
\hline 28 & excellent & 45 & 28 & pond & 50 & 28 & friendly & 55 & 28 & artist & 38 \\
\hline 29 & healthy & 42 & 29 & wonder & 45 & 29 & poor & 52 & 29 & sign & 33 \\
\hline 30 & fantastic & 41 & 30 & market & 45 & 30 & scenic & 51 & 30 & performance & 28 \\
\hline
\end{tabular}


Among the top 30 high-frequency words in Table 3 that characterize the tourist's perceived tourism image and the DMO's projected tourism image, 14 adjectives are repeated, with an overlap of $46.7 \%$, and 13 nouns are repeated, with an overlap of $33.3 \%$. Through the three-level theoretical coding of the above high-frequency words, 13 open coding elements of DMO projected tourism image were obtained, including "geographical location", "ethnic minority culture", "image brand/label", "karst topography", "longevity, health and natural resources", "longevity, health and cultural resources", "landscapes", "people”, "social life and atmosphere", "tourist attractions", "tourist infrastructure", "tourist service" and "tourist activities"; four dimensions of axial coding are involved, including "places", "natural and social environment", "health destination characteristics/environment" and "tourist characteristics/environment". The results of the analysis of the tourist and DMO image data show that the images mainly show the Bama TDI system since no new theoretical coding emerged, indicating again that the theory has reached saturation.

\subsubsection{Dimension Analysis of Cognitive Components}

Cluster analysis of the top 30 high-frequency words obtained from the parsing of tourist and DMO release images revealed that the main elements perceived by tourists include natural scenery $(32.15 \%)$, people $(18.08 \%)$ and places $(11.41 \%)$, while the main elements promoted by DMO release images include natural scenery $(41.69 \%)$, people $(21.95 \%)$ and facilities (accounting for $13.02 \%$ ). We selected one representative picture from each category of elements (see Figure 2) to further analyze their contents and compare the differences between tourists' and DMOs' perceived images of Bama. The selection of representative images abides by the following principle, i.e., if there are at least five images with similar content in the dimension involved, the image can be used as a representative image content for that dimension.

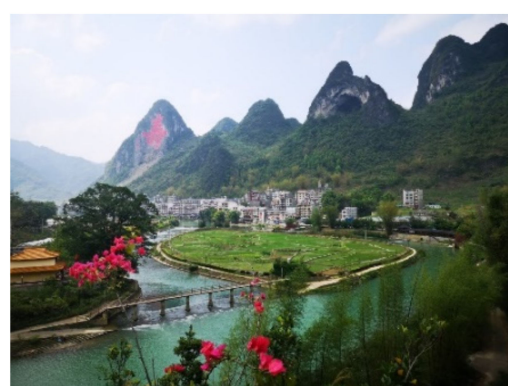

(a)

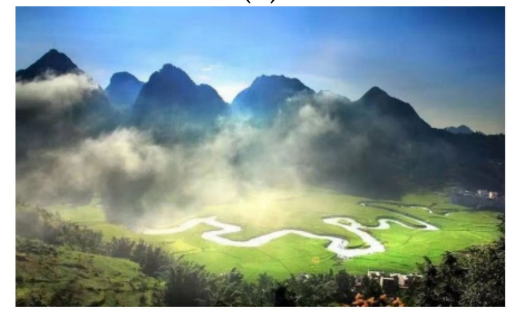

(d)

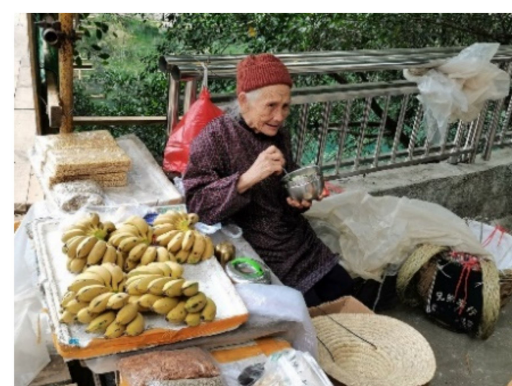

(b)

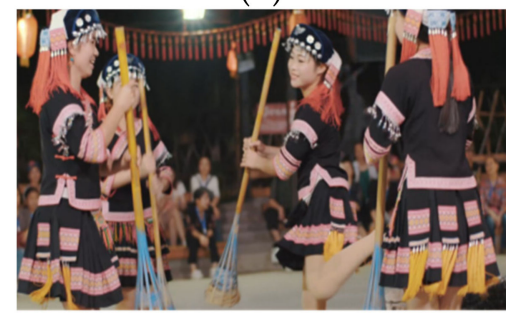

(e)

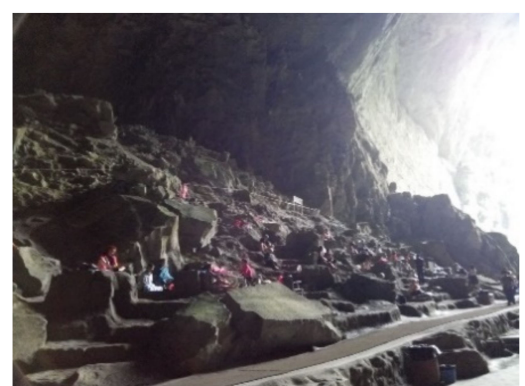

(c)

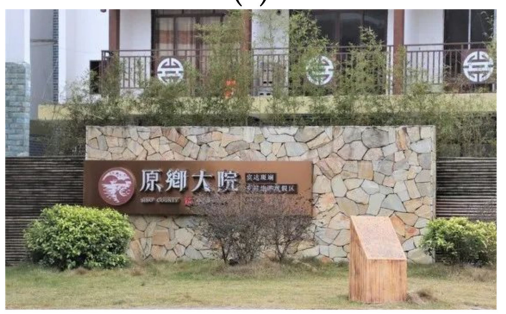

(f)

Figure 2. Typical photos taken by tourists and DMO: (a) Photos of natural scenery by tourists; (b) Photos of people by tourists; (c) Photos of places by tourists; (d) Photos of natural scenery by DMO; (e) Photos of people by DMO; (f) Photos of tourist facilities by DMO.

Photos of natural scenery. Although both the tourist and the DMO capture images contain a large number of natural scenic landscapes of karst landscapes, there are some differences in the content of the specific images (e.g., Figure 2a,d). The natural scenery pictures taken by the tourists mainly visualizes the karst geological wonders of the main tourist attractions such as Baimo Cave, the Hundred Birds Rock (Bainiao Rock) and the Crystal Palace, as well as the landscape near the longevity villages, in Figure 2a. While the 
natural scenery pictures promoted by the DMO are mainly iconic landscapes that the DMO is committed to creating, showing not only the geological features of Bama, but also the cultural features of the longevity township, such as the Life River shown in Figure 2d, which resembles a giant cursive Chinese character "Life" when viewed up above. According to the data of local statistics department, the number of people over 100 years old living in the river basin accounts for more than two-thirds of the total number of centenarians in Bama.

Photos of people. There are visiable differences in the content of the people images captured by tourists and those delivered by the DMO. The content of the tourist shots are mainly tourist selfies, living places related to local residents and sojourners (e.g., Figure 2b), with particular attention to the long-lived elderly, while the content of the DMO publicity pictures are mainly long-lived elderly showing the brand of "land of longevity worldwide", and staff participating in local cultural exhibitions (e.g., Figure 2e).

Photos of places. The place element is the content that is more frequently shown in pictures taken by tourists, mainly including recreation places and living places, such as the magnetic therapy area where sojourners and tourists meditate and inhale oxygen in the Baimo Cave in Figure 2c. In addition to outdoor recreation sites at major tourist attractions, the places photographed also involve places where local centenarians live (e.g., centenarians' homes), places where minority cultures are displayed (e.g., performance areas), and places closely related to longevity and wellness features (e.g., locations where sojourners intake spring water).

Photos of facilities. Tourism-related facilities are important elements in DMO publicity pictures, mainly including accommodation, catering, excursions and other tourism service facilities, such as the homestay hotel photographed in Figure $2 \mathrm{f}$.

\subsubsection{Analysis on Emotional Image Embodied in the Picture}

With regard to the emotional image of the destination expressed by tourists in pictures, the top 30 adjectives are all positive. The first five adjectives are "misty", "ancient", "natural", "famous" and "stunning", with "misty" expressing mainly the sentiment of "climate", "ancient" expressing emotions towards "ethnic minority culture", "famous" expressing the sentiment towards "image brand/label" and "stunning" mainly expressing the sentiment towards "landscapes". Regarding the emotional image of the destination expressed by the DMO images, the first five adjectives are "traditional", "healthy", "super", "outdoor" and "great" among the top 30 high frequency adjectives. Since DMO has been committed to making Bama a health and wellness tourism destination, "healthy" is the most appropriate sentiment for the Bama TDI. Thereinto, "traditional" mainly expresses the emotion of "ethnic minority culture" and "social life and atmosphere", "healthy" mainly expresses the emotion of "people", "super" mainly expresses the emotion of "landscapes", "poor" mainly expresses the emotion of "tropical", "super" expresses the emotion of "landscapes", "outdoor" expresses the emotion of "tourist activities", and "great" expresses the emotion of "people".

\subsection{Representation of Bama's TDI Based on UGC}

Based on the tourist and DMO text and image data, we preliminarily construct a theoretical coding system to represent the image of tourist destinations. At the same time, in order to weaken the value interference caused by individual researchers' preferences, we interviewed another 10 researchers (including 2 professors, 2 associate professors, 3 doctoral students and 3 master students in the field of tourism research), and combined their opinions to form the final theoretical coding system.

Comparing the elements from exploratory work with existing theories, we found a concept "intention to recommend" in the studies of Stylidis et al. [34], Qu et al. [35], which was not extracted from the exploratory research. Behavioral intention was estimated by Stylidis et al. [34] in the model which shed light on the destination image formation process of residents by incorporating the cognitive and the affective components of image. It is proved that cognitive, affective and overall images influence future behavior (intention 
to recommend), and "intention to recommend" is included in measurement scales for destination image by Stylidis et al. [34]. According to the selective coding in our research, we extract the keywords related to future behavior again and obtain two tendencies: recommend-won't recommend and return-won't return.

In summary, the tourism image measurement scales of the health destination constructed by us are as follows (Table 4 ):

Table 4. Measurement scales and literature sources.

\begin{tabular}{|c|c|c|c|}
\hline Selective Coding & Axial Coding & Open Coding & Source \\
\hline \multirow{3}{*}{ Spatial/Place components } & Places & $\begin{array}{l}\text { Geographical location } \\
\text { Health and recreational areas }\end{array}$ & $\begin{array}{c}{[29,36]} \\
{[19]}\end{array}$ \\
\hline & $\begin{array}{l}\text { Accessibility/supporting } \\
\text { infrastructure }\end{array}$ & $\begin{array}{c}\text { Access } \\
\text { Transportation }\end{array}$ & $\begin{array}{c}{[37]} \\
{[19,38]}\end{array}$ \\
\hline & Natural topography & Karst topography & {$[11,29]$} \\
\hline \multirow{3}{*}{$\begin{array}{l}\text { Cognitive components } \\
\text { (Based on placeness) }\end{array}$} & Natural and social environment & $\begin{array}{c}\text { Longevity, health and natural resources } \\
\text { Longevity, health and cultural resources } \\
\text { Climate } \\
\text { Landscapes } \\
\text { Ethnic minority culture }\end{array}$ & $\begin{array}{c}{[37,39]} \\
{[40]} \\
{[41]} \\
{[36]} \\
{[40,42]}\end{array}$ \\
\hline & $\begin{array}{l}\text { Health destination } \\
\text { characteristics/environment }\end{array}$ & $\begin{array}{c}\text { Image brand/label } \\
\text { People } \\
\text { Social life and atmosphere }\end{array}$ & $\begin{array}{c}{[29]} \\
{[15,27,43]} \\
{[19,36]}\end{array}$ \\
\hline & $\begin{array}{c}\text { Tourist } \\
\text { characteristics/environment }\end{array}$ & $\begin{array}{l}\text { Tourist attractions } \\
\text { Tourist infrastructure } \\
\text { Tourist service } \\
\text { Tourist activities }\end{array}$ & $\begin{array}{c}{[41]} \\
{[6,21,34]} \\
{[4,34]} \\
{[43-45]}\end{array}$ \\
\hline \multirow{4}{*}{ Affective components } & Imagery & $\begin{array}{c}\text { Extraction and conceptualization: } \\
\text { Xanadu/Arcadia, poetic and picturesque, } \\
\text { fairyland }\end{array}$ & {$[42,46]$} \\
\hline & Experience assessment & $\begin{array}{l}\text { Extraction and conceptualization: feeling, } \\
\text { supernatural, unique, appreciation, taking a } \\
\text { picture, holy land, spectacular, worthy, } \\
\text { impression, mood, mysterious, lively and } \\
\text { fun, pity/disappointing }\end{array}$ & {$[5,34,43,46,47]$} \\
\hline & \multirow{2}{*}{ Future behaviors } & Recommend-won't recommend & \multirow{2}{*}[6,35,37,43]{} \\
\hline & & Return-won't return & \\
\hline
\end{tabular}

\subsubsection{Spatial/Place Components: Placeness Basis of TDI Construction}

Destination image is an important embodiment of discovering local landscape and local significance, and its essential meaning is the presentation and interpretation of locality [48]. When it comes to a destination, the first thing travelers focus on is its geographical location. For a place of health, unique regional characteristics are the placeness basis for the formation of a destination's tourism image. Bama is located in the south-western frontier and is relatively isolated, thus becoming "a piece of God's pure land left on earth", with the proportion of long-lived people over 100-years-old of age per 100,000 people, far exceeding the standard of the "the land of longevity worldwide". It is this remote, isolated and relatively enclosed location that has allowed the pristine nature and longevity lifestyle of the region to be steadily preserved. In addition, Bama's unique karst topography has created a unique environment for the formation of the "longevity and health" image. In addition, the unique karst topography of Bama creates natural conditions for the image of "longevity and health".

The interaction between place and people is a necessary means of communication in the construction of "health and recreational" places. Many places have been transformed 
from living spaces for locals to health and recreational areas for tourists and sojourners. Places, natural topography, accessibility (the combination of location and topography and the accessibility influenced by this) effectively characterize the physical and geographical features that underpin Bama as a health place.

\subsubsection{Cognitive Components: TDI Building and Performance Based on Placeness}

It is common practice for destinations to produce attractive cultural symbols to attract tourists by embedding localities into positioning the image of the destination [48]. Bama's geographical location, natural and cultural regional characteristics form the basis of tourists' cognition of Bama's TDI. The high frequency words, the first group including "water", "sunlight", "geomagnetism", "air", "negative oxygen ions", "climate", "mountains-andwaters", "scenery" and so on, reflects the natural characteristics of Bama's longevity and health tourism destination. The second group including "minority", "Yao Village", "Yao Autonomous County", "Yao nationality", "Zhuang nationality", "the March 3rd of the lunar calendar" reflects the ethnic cultural characteristics of Bama as Yao Autonomous County. The last group including "longevity village", "longevity culture", "replenish food and increase longevity", and "red pocket" reflects the cultural characteristics of the longevity and health.

The unique natural and cultural environment of Bama provides a good place for the social interaction between tourists and the tourist destination, which delivers the external display and characteristics of a place whose overall visual appeal is a joint construction of environment, landscape, culture and industry, with a significant local identity, resulting in the formation of symbols and signs for tourists to promote the TDI of Bama, namely, "longevity", "health preservation", "land of longevity", "benevolence and longevity". The interaction between place and people promotes and facilitates the production and integration of the environment or atmosphere for health preservation; among them, "people" include tourists, sojourners, centenarians and other natives, and tourist-related operators. The establishment and enhancement of different types of subject relationships break through the physicality of the place, making its unique place characteristics and atmosphere a concrete expression of the local characteristics of "longevity and health". For example, the interaction between the centenarians and the tourists in the longevity village on the banks of the Pangyang River is a concrete environment and way in which sojourners and tourists can experience longevity and health. This unique placeness and atmosphere is expressed by the tourist and the DMO as "laid back" and "slow life". "Social life and atmosphere" emphasize the overall "natural and cultural environment" as an external link, through the tourist's in-depth experience of "social life and atmosphere" to feel the "laid back" and "slow life" atmosphere of Bama. Meanwhile, it deepens the perception of the longevity and health TDI of Bama by use of tourist infrastructure, the appreciation of tourist attractions, the participation in tourist activities, the experience of tourist service and the human connection.

\subsubsection{Affective Components: Feelings and Follow-Up Behavior}

The idea of affective destination image was introduced into the literature and the focus of subsequent analyses in this field was shifted from pure cognition-driven to a combination of cognition and affective studies in destination image studies [10]. Cognitive destination image refers to the subject's perception of the attributes of a tourism destination, while affective destination image refers to the emotional responses of subjects to the place [12].

Place-based cognitive images influence the tourist's perception and expression of the emotional image of the destination [34]. Like places, tourist places are subjective spaces where the human tangible experience is extremely important to connect with the placeness, and for tourists, with the integration of personal tangible experiences, the normal tourists regard Bama as a supernatural, unique, mysterious, spectacular and worthy place to go to. Thus, Bama is no longer an irrelevant public space, but an imagery of Xanadu/Arcadia, poetic and picturesque, fairyland, as it is called in the tourist's travelogue, which is also 
transformed emotionally into a continuous act of nostalgia, of not wanting to leave, or of sharing. Further exploration of the text reveals key words such as "return", "recommend", "linger", et al. that express positive affection indicating the follow-up behavior. In contrast to these positive affective states, the over-commercialization of tourism development in "Longevity village" has led to a minority of travelers perceiving Bama as a health destination as "disappointed and won't return".

The keyword "sojourners" appears 193 times in tourist texts. For them, a long stay in a foreign place to recuperate, like migratory birds, leads to shared experiences and memories, an inseparable emotional attachment to the place, and even a strong "rootedness" like home [40]. Far away from home to a strange place, like, stay, live, or even maintain a long-term sojourn state, no doubt shows the identification and attachment to the lifestyle and local atmosphere of the place.

In summary, from the overall results of the textual analysis, the tourism image of Bama as the "land of longevity worldwide" presents three main dimensions of spatial/place, cognitive and affective as well as the specific presentation of "places", "accessibility/tourist characteristics/environment", "natural topography", "natural and social environment", "health destination characteristics/environment", "tourist characteristics/environment", "imagery", "experience assessment", and "future behaviors". Among them, the unique geographical and local characteristics create the placeness basis for the construction of TDI for health destination. The layers of "natural and social environment", "health destination characteristics/environment", and "tourist characteristics/environment" deepen the perception and understanding of Bama's TDI, thus forming the emotional expression and behavioral continuity of tourists towards the destination, which is also the deep identification with the image of the "land of longevity worldwide".

\subsection{Analysis on Characteristics of Representational Power for Bama's TDI}

\subsubsection{Representational Mechanism}

Balshaw and Kennedy [2] argue that place is the result of representation and that how it is represented is controlled by the choices of human society, and that what makes a "place" a tourist destination is in fact a historical choice, the concentrated expression of the will of a certain social class and its representatives. Liu [9] argues that the process of representation of tourist places is an act of cultural reproduction, in which the natives, DMOs and touristrelated operators, and tourists jointly reconstruct the place and form a "non-real world". Foucault argues that the will of the dominant class in the process of co-construction of TDI is expressed through a "discourse" that hides complex power relations [9]. Based on Foucault's power theory, this paper analyzes the formation mechanism of TDI in Bama and the characteristics of its representational power.

- The formation of health concept and regional characteristics

According to CCTV, Bama has healthy water, air and magnetic strength of the earth. The water in Bama is weakly alkaline, which is good for human body. The air has a high concentration of negative oxygen ions. The concentration of negative oxygen ions along the Panyang River and in the mountains and forests in Bama is 10,000 to 30,000 ions per cubic centimeter, and in the Baimo Cave, it is 60,000 to 90,000 ions per cubic centimeter. In contrast, the concentration in the city is only 200-300 ions per cubic centimeter. The daily activities of health tourists in Bama are mainly centered on natural health attributes such as water, air, and geomagnetism [40]. This has been the unique advantage of Bama as a place of recuperation in the official propaganda all along. The remote geographical location and unique natural environment have created a simple atmosphere and wellness environment, and the uncontested people's mentality has made leisure, slow pace and healthy diet a naturally formed and internalized lifestyle that has been passed down from generation to generation. Bama's natives follow the Confucian tradition of respecting the elderly, and have the custom of "making up food" and "preparing coffins" for the elderly over 60 years old, and the old people have been working, not at home to enjoy the benefits. Compared to the affluent life of modern urban civilization, although the local residents of Bama are 
not economically affluent, their longevity also comes from their inner affluence and the pursuit of leisure life. After the development of tourism, a large number of sojourners flock into the longevity village, the pursuit of natural and leisurely life continues, thus forming Bama's health philosophy of pursuing a slow pace and longevity, as well as his longevity and health culture with "Bama phenomenon" as its obvious feature.

- Building and strengthening the health atmosphere

Culture plays an important role in shaping the relationship between place and health. The cultural symbol landscape of Bama presents the influence of Chinese longevity culture and traditional Chinese medicine culture, which is also the symbol system for Bama to become a longevity and health care destination [40]. At the outset of the emergence of Bama health tourism, not many people knew about it, and it was mostly spread by word of mouth. As tourism grew, so did her reputation, and so did the crowds. In order to protect the local natural environment and longevity culture, the local government established the Management Committee of Bama Longevity and Health International Tourism Zone and issued the Regulations on the Protection of the Ecological Environment of Panyang River Basin, which provides a legal basis for its subsequent protection and improvement. The government develops health tourism products, routes and activities to encourage local residents to integrate into the development of tourism. We can see the tolerance, nature and slow-paced mentality of local residents from the activities of tourists visiting the long-lived elderly. Combined with the poverty alleviation mechanism and Shenzhen to jointly build the "Shenzhen Bama Great Health Cooperation Special Pilot Zone", the longevity and health culture has been continued. In addition, the government also carries out tourism promotion with the theme of "the hometown of longevity in the world" and "longevity sanctuary, regimen paradise", vigorously advocates and supports the business operation with regimen tourism as the theme, and vigorously creates the regimen atmosphere in the main tourist spots, which provides support for the subsequent construction of operators. Thanks to the rise of traditional Chinese medicine health resorts, all kinds of health apartment and home-stay, tourists are unconsciously infected by the health atmosphere here, according to the "health label" to experience. The high-frequency words such as "Baimo Cave", "Ming River", "spring", "magnetic therapy" and "oxygenation" represent the health preservation symbols of Bama, highlighting the symbol meaning and symbol presentation in the image representation of Bama's tourism. These "health labels", together with the "health elements" created by DMO and the tourists' "health experience", jointly strengthen the TDI of Bama as a health destination.

- Health experiences in the uncustomary environment

Some of the earliest tourist operators were actually tourists who came to Bama for recreation and settled here because they liked the unique health environment and the slow-paced life here. Their purposes are to keep healthy and to leave the fickleness of metropolis to live in peace and leisure. Influenced by the cultural atmosphere of the natives, they gladly enjoy the slow life here and quickly blend in. Bama not only belongs to the local residents, the government and the first immigrants, but also belongs to the subsequent foreign tourists and sojourners. The tourism spatial structure of the whole place is also constantly changing under the influence of foreign groups and their different cultures. Thus, longevity and health preservation culture have been continuously strengthened, and Bama phenomenon has become the embodiment of Chinese health preservation values. There are many villages in China with excellent environments, but Bama stands out from the rest of the countryside and attracts so many health tourists because of its brand of "longevity town" [40].

A tourist destination means an unfamiliar place to the visitor, and to blend in as quickly as possible, tourists tend to ask other sojourners for information about every aspect of it. Newcomers will inquire, observe, and imitate the practices of old visitors, such as fetching water, drinking water, magnetic therapy, oxygen, walking, etc. Tourists spend more time outdoors in Bama than usual, which increases their chances to communicate 
with others. The most common communication among tourists is the discussion on the health preservation properties of Bama, spreading the miraculous cases of healing in Bama by people around, sometimes you can even see him, so that the tourists who get this have a deep belief in the magical health preservation properties of Bama. The sojourners that the travel writers met in Bama are themselves the landscape of the health preservation destination. They jointly create, strengthen and prove the health preservation properties of Bama.

\subsubsection{Characteristics Analysis on Representational Power}

\section{- Government departments have absolute power of representation}

Under the socialist market economy system, DMO has the decisive power of cultural representation. As "the hometown of longevity in the world", the slogan of "the benevolence and longevity Bama blessed by heaven and earth" and "the leader of healthy China in the new era" both reflect the will of DMO. In order to attract tourists, promote the destination development to match these slogans, the DMO encourages tourism enterprises to infiltrate the culture of health and wellness into the creation of local cultural landscape, and has formulated the "Bama health industry development planning", "The All-Around tourism development planning" and a series of incentives and policies. In order to strive for these incentives and preferential policies, operators have demonstrated their catering to the government's representational powers, placing emphasis on the creation and enhancement of a longevity and health atmosphere and the provision of health tourism products and services.

- The influence of tourists' representation power in cyberspace is enhanced

Influenced by personal experience, the knowledge structure, consumption habits, behavioral preferences and level of access to pre-travel information, online travelogues formed by travelers returning to their usual environment and portraying Bama often incorporate positive or negative emotional overtones, thus drawing a picture of the tourist space and destination as perceived by the travelers as the "self". The texts and pictures of travelogues contain a large number of cultural landscape symbols such as natural landscape, architecture, clothing and food. These landscape symbols are the true expression of their images of tourism space and tourist destinations, and also the extension form of Bama's health culture and tourism space reproduction. Like DMO, these authors of travelogues have participated in the production of Bama's tourism image and tourism space as the representational subjects of tourism destinations. In the early 1990s, Bakos [49] argued that the rise of the internet would eventually shift the power structure of buyers and sellers completely toward buyers. More than two decades of social and economic practices have confirmed Bakos's view that in the market of supply and demand, and consumers are no longer only the ones who unilaterally receive marketing information. Kozinets [50] believes that consumers have the power to change other consumer decisions and even the product itself. Consumers' behaviors and habits affect the development and design of products, service process reengineering and even the choice of marketing channels and methods. Existing studies also believe that with the rise of tourists' power, tourists convey the identity and image of Bama as a health destination to "others" through texts and pictures, and influence the decision-making tendency of "others" to different degrees [51].

- The centenarians have the most significant influence on the representation power of local residents

Tourists and DMO texts have described the pursuit of ease and leisure for local residents in Bama. For example, "I noticed an incident once drivers with vehicle license number tend to honk their horns in a hurry when stuck in traffic, while the natives driving tricycles or motorbikes wait in line quietly and without panic" (netizen Wanze from Ctrip), "The scenery along Bama is still very beautiful, with few people in this street, the villagers are so peaceful. A villager keeps a large rooster that rests like its owner, and we don't hear it crow until twenty to nine in the morning" (netizen Yanyu from Mafengwo), and all these 
reflect the laid back social life and atmosphere of the destination. Among local residents, "centenarian" is the most influential representation of Bama's TDI. Tourists come to Bama to explore the secrets of "the hometown of longevity in the world", visit the centenarians, learn about their daily life, feel the cultural atmosphere of longevity, and ask for the secrets of longevity as often a necessary activity [40]. "Centenarian" is the signified of Bama as the hometown of longevity is the symbol of the image of health tourism, but also the image of longevity health tourism communicator. To make it easier to find the homes of centenarians, the local authorities have created huge posters with information about centenarians and directions to their homes. The high frequency word "centenarian" appears 295 times in the tourist text, indicating that visiting the centenarians is an important tourist activity when visiting Bama.

To sum up, the longevity and health tourism image of Bama is formed by the joint creation of local residents, especially centenarians, DMO and operators, and tourists. In other words, with the common identity of internal and external groups in Bama, the longevity and health tourism destination image based on the locality is formed. The natives live in Bama for thousands of years, which have followed and inherited their health customs and culture with perseverance and consistency, and some centenarians have never left Bama in their whole life. This is the local foundation of the image of Bama health tourism, and the spiritual background of its health culture also comes from this. To attract tourists, DMO and tour operators construct or represent the tourist space and image in different ways under the stimulation of their own interests and needs. Bama Health TDI is the common product of stakeholders as mentioned above (Figure 3).

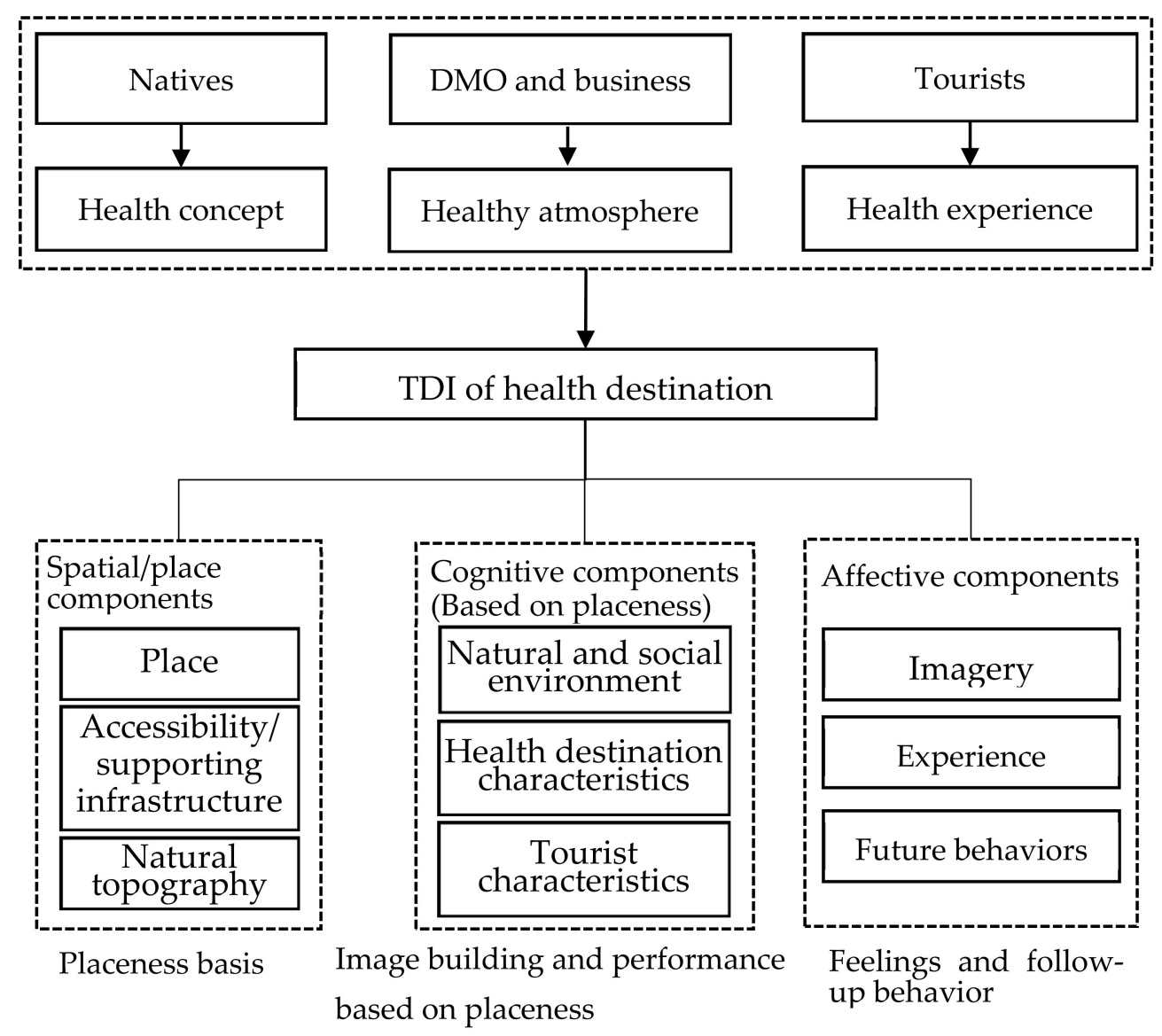

Figure 3. Schematic diagram for formation mechanism of Bama's TDI. 


\section{A Comparative Analysis on Projected and Perceived Image Based on IPA Method}

\subsection{Overall Results Based on IPA Analysis}

The scores for the degree of importance of DMO cognitive elements, i.e., "importance axis" (I), and the degree of performativity of tourists on important elements, i.e., "performance axis" $(\mathrm{P})$, were obtained using the high-frequency word data from the text parsing through the formula. To reveal the difference between DMO projection image and tourist perception image more intuitively, a two-dimensional coordinate graph (Figure 4.) is constructed with I value and $\mathrm{P}$ value respectively, in which four quadrants are divided with $\mathrm{P}=3.281$ and $\mathrm{I}=0.4706$ as the origin, and 20 elements of open coding are drawn in different quadrants according to I-P value. Among them, the larger the value of I, the more important DMO considers it, and the larger the value of $\mathrm{P}$, the more tourists perceive it. It should be noted that, due to the small number of pictures released by Bama DMO and tourist, there are fewer categories of tourism perception images obtained in dimension analysis than that in text analysis. Therefore, the data analyzed by IPA model only uses travel notes and DMO texts. Furthermore, the frequency of keywords included in the research scope is more than 20. The I value and P value of each Dimensions for Bama's TDI is listed in Table 5.

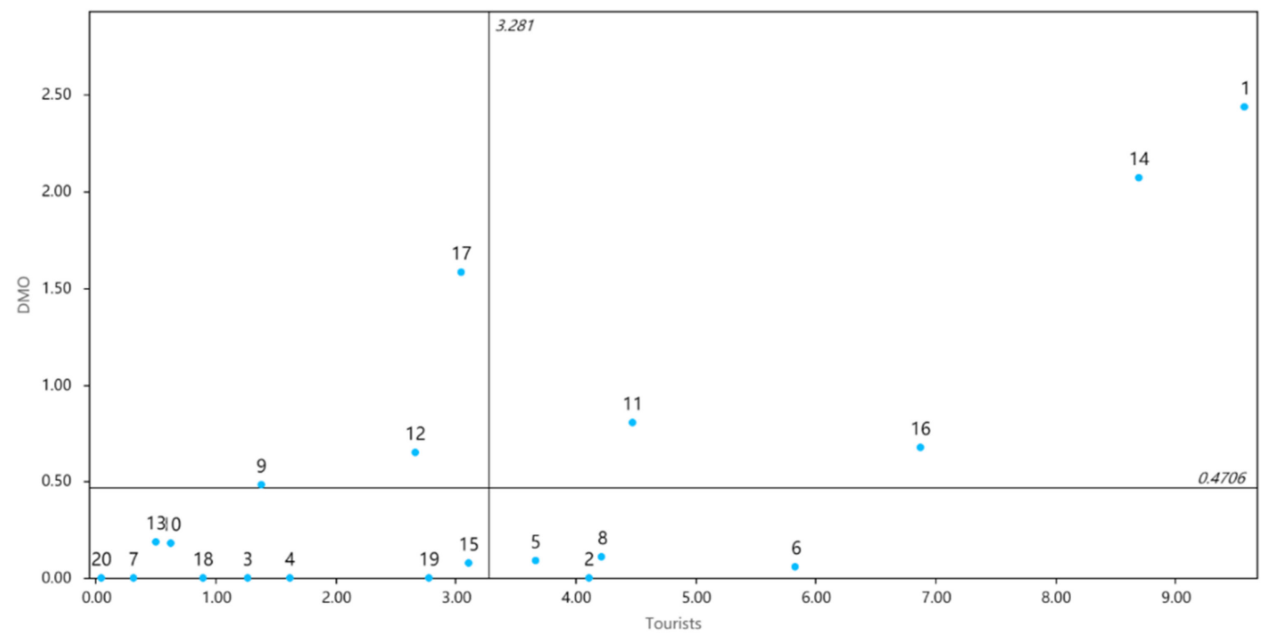

Figure 4. Distribution of I-P Values of Perception Factors of Tourism Image in Bama: The first quadrant (Continue to strengthen): "Geographical location", "image brand/label", "tourist attractions" and "tourist service"; The second quadrant (Focus on improvement): "Ethnic minority culture", "people" and "tourist activities"; The third quadrant (Opportunity image): "Access", "transportation", "climate", "longevity, health and cultural resources", "social life and atmosphere", "tourist infrastructure", "imagery", "experience assessment" and "future behaviors"; The fourth quadrant (Do not deliberately improve): "Health and recreational areas", "karst topography", "longevity, health and natural resources" and "landscapes".

According to Figure 4, for importance axis, the value of "geographical location", "ethnic minority culture", "image brand/label", "people", "tourist attractions", "tourist service" and "tourist activities" exceeds the I-value mean, which indicates that the tourism image projected on DMO attaches importance to the promotion of the above factors and believes that these factors can represent the tourism image of Bama as a health destination. The rest of the categories are below the mean and are less promoted by the DMO. The value of "geographical location", "health and recreational areas", "karst topography", "longevity, health and natural resources", "landscapes", "image brand/label", "tourist attractions" and "tourist service" exceeds the P-value mean. It shows that tourists have more perceptions of the above factors. The rest of the categories are below the mean value, indicating that tourists perceive them relatively less. 
Table 5. The I value and P value of each Dimensions of TDI.

\begin{tabular}{cccc}
\hline No. & Dimensions of TDI & I Value (DMOs) & P Value (Tourists) \\
\hline 1 & Geographical location & 2.4391 & 9.5756 \\
2 & Health and recreational areas & 0.0000 & 4.1092 \\
3 & Access & 0.0000 & 1.2626 \\
4 & Transportation & 0.0000 & 1.6134 \\
5 & Karst topography & 0.0924 & 3.6639 \\
6 & Longevity, health and natural & 0.0588 & 5.8298 \\
7 & resources & 0.0000 & 0.3088 \\
8 & Climate & 0.1113 & 4.2164 \\
9 & Landscapes & 0.4811 & 1.3761 \\
10 & Ethnic minority culture & 0.1786 & 0.6176 \\
11 & Longevity, health and cultural & 0.8067 & 4.4685 \\
12 & resources & 0.6471 & 2.6576 \\
13 & Image brand/label & 0.1870 & 0.4958 \\
14 & People & 2.0735 & 8.6975 \\
15 & Social life and atmosphere & 0.0798 & 3.1050 \\
16 & Tourist attractions & 0.6765 & 6.8718 \\
17 & Tourist infrastructure & 1.5798 & 3.0483 \\
18 & Tourist service & 0.0000 & 0.8887 \\
19 & Tourist activities & 0.0000 & 2.7731 \\
20 & Imagery & 0.0000 & 0.0399 \\
\hline
\end{tabular}

\subsection{Comparative Analysis on Projected and Perceived Image}

\subsubsection{The First Quadrant: Continue to Strengthen}

The first quadrant refers to continue to strengthen the area, which includes four factors: "geographical location", "image brand/label", "tourist attractions" and "tourist service". The cognition of these four factors, whether DMO promotion or tourists' perception, is higher than the average level, which shows consistency with each other. On the one hand, DMOs have been more effective in recognizing and promoting the core elements of tourism such as "geographical location", and "image brand/label". On the other hand, DMO is more effective in cognition and promotion of tourism core elements such as "tourist attractions" and "tourist service", which are also the elements that tourists perceive more often. In summary, with the strong promotion and publicity by DMOs, the above five factors are more prominent and are factors that need to be maintained and strengthened.

\subsubsection{The Second Quadrant: Focus on Improvement}

The second quadrant is the area to focus on improvement, including "ethnic minority culture", "people" and "tourist activities" which are the factors that DMO projection is higher than the average level while tourists' perception is lower than the average level, which indicates that DMO and tourists have perceptual deviations on the above two elements. Both tourism publicity and tourism development need to be improved. Bama is a Yao autonomous county, and the ethnic minority culture is its rooted regional culture, which is the key promotion content of DMO. However, the low perception of "ethnic minority culture" by tourists is probably due to the desynchronized status between the DMO's promotion and development of minority culture, which indicates that the existing tourism products need to be strengthened in terms of minority culture representation. Among the "people" elements, the most prominent keywords are "local" and "centenarian", and tourists have less perception of the "people" elements, which shows that even though visiting centenarians is an important part of Bama tourism activities, compared with sightseeing, oxygen inhalation, water fetching and other health-preserving experiences, the latter is a leisure and recreation method that more tourists pursue. "Tourist activities" is one of the core elements that tourists focus on, and it needs to improvement and upgrades to meet the diversified markets. 


\subsubsection{The Third Quadrant: Opportunity Image}

The third quadrant is the opportunity image area, including "access", "transportation", "climate", "longevity, health and cultural resources", "social life and atmosphere", "tourist infrastructure", "imagery", "experience assessment", and "future behaviors". DMO and tourists show consistency in cognition and representation of the above elements, but these factors are lower than the average level in both DMO projection image and tourist perception image, indicating that it is insufficient for both promotion of these elements by the DMO and perception of these elements by the tourist during their stay in Bama. The improvement of accessibility factors such as "access", "transportation" and "tourist infrastructure" are important factors influencing the development of tourism in Bama. Bama's climatic conditions are suitable for health care and living, the "social life and atmosphere" is comfortable and leisurely, the profound health care culture and the imagery of "Xanadu/Arcadia" are beautiful, making "climate", "longevity, health and cultural resources", "social life and atmosphere" and "imagery" to become natural and social factors to attract tourists. Previous studies have incorporated "future behaviors" into tourism image measurement scales [34], arguing that "future behaviors" helped to increase wordof-mouth and to attract new tourists to the destination [34,35]. Moreover, the promotion of "experience assessment" reinforces the positive "future behaviors" of the tourist. In summary, the above factors are opportunities for the promotion and improvement of Bama's TDI, and improvements should also be focused on.

\subsubsection{The Fourth Quadrant: Do Not Deliberately Improve}

The fourth quadrant is called "do not deliberately improve" area, which contains factors of "health and creative areas", "karst topography", "longevity, health and natural resources" and "landscapes". The elements in this quadrant are less advertised by DMOs but have a high level of perception by tourists and are among the elements where there is a greater difference in perception between DMOs and tourists. However, as these elements can be perceived to a high degree by tourists without strong DMO promotion, there is no need for deliberate improvement.

\section{Discussion}

The knowledge contribution of this paper that breaks through previous TDI construction studies is that it emphasizes exploring the composition and classification of TDI components from the regional characteristics and constructing a multidimensional measurement system of TDI that meets the characteristics of health destinations. Under this system, the TDI of health tourism destinations can be presented by spatial/place, cognitive, and affective components, among which the spatial/place component includes "places", "accessibility/supporting infrastructure" and "natural topography", and the cognitive component includes "natural and social environment", "health destination characteristics/environment", "tourist characteristics/environment", and the affective component includes "imagery", "experience assessment", and "future behaviors". Among them, unique locational characteristics are the local basis of Bama TDI, cognitive image is the process of image building and performance based on placeness of Bama health tourism image, and effective image is the feeling of Bama tourism experience and shows up as follow-up behavior. Compared to previous studies $[4,6,10,12,16,21,34,35]$, our analytical framework emphasizes that tourism image construction should be formed based on unique location and sense of place. Among which, Stepchenkova et al. [11] compared the cultural difference in the pictorial image of Russia through the camera lenses of American and Korean tourists, and extracted "place" and "space" as first-order categories of TDI, However, Stepchenkova et al. [11] simply constructed the category of cognitive TDI. Furthermore, among the thirdorder elements obtained through keyword conceptualization, "image brand/label" and "social life and atmosphere" are less frequently analyzed in previous studies. The analysis of affective images was done by determining positive, negative and neutral emotions, in addition, the dimensions of "imagery" and "experience assessment" were identified from 
the keyword analysis. To maintain the continuity of the research framework, the dimension of "future behavior" was added to the study of Stylidis et al. [34], which enriched the connotation of the TDI construction study. This is the first knowledge gap our study makes.

This study focuses on analyzing the formation mechanism of health tourism destinations from a process perspective. Based on the theory of discourse power put forward by Michel Foucault, this study aims to figure out how the TDI of UGC-based health tourism destinations are represented and formed under Michel Foucault's discourse power theory. The TDI of Bama, which is as a health destination, is co-constructed and represented by the natives, DMO and tourist-related operators, and tourists. The health concept formed by the aborigines through history and culture is the local and spiritual foundation of Bama's TDI, and for sustainable development, it is the first and foremost mission to protect the local longevity resources, especially the centenarian residents, to maintain the reputation of Bama's TDI. DMOs and tour operators make their health image stronger and more vivid by marketing and creating the atmosphere to attract tourists; tourists' health needs are satisfied in the tourism experience of visiting Bama, so that the health characteristics of its tourism image can be more visible under the boost of their identity. This is the second knowledge gap our study makes.

In addition, this study used the IPA method to visually reveal the differences between the projected image of DMO and the perceived image of tourists, and obtained the following elements that are consistent between $\mathrm{DMO}^{\prime} \mathrm{s}$ and tourists' perceptions: "geographical location", "access", "transportation", "climate", "longevity, health and cultural resources", "image brand/label", "social life and atmosphere", "tourist attractions", "tourist service", "tourist activities", "imagery", and "future behaviors". Among them, "access", "transportation", "climate", "longevity, health and cultural resources", "social life and atmosphere", "imagery", and "future behaviors" are the opportunity elements located in the third quadrant, which should be focused on to improve with "ethnic minority culture" and "people" that are located in the second quadrant. This is the practical significance of this study. It can further strengthen tourists' perception by replacing the image symbols of the tourist destination disseminated by DMO and its official agencies with those symbols representing the image of a health destination in which tourists participate in production. It can further strengthen the perception of tourists after the trip and help them reproduce the tourism space from the "self" in the form of publishing travelogues or guides.

Although health destinations have become popular demand after the COVID-19 epidemic, the amount of online data obtained is limited due to the fact that Bama is a niche tourism destination with far less UGC data than mainstream tourism destination cities, bringing certain limitations to the study. The research in this paper is exploratory, and further quantitative research and empirical tests would validate whether the constructed measurement scales of TDI system for health destinations are consistent with the reality and use importance grid analysis (IGA) to improve the IPA analysis [52-54]. In addition, as a health tourism destination, Bama's tourism market includes two levels, which are the mass tourists and the health tourists (i.e., the sojourners). The mass tourists stay for a short time and aim at sightseeing or short-term vacation, while the health tourists aim at leisure and health and stay for a long time, often staying for half a year or even longer. This study attempts to compare the differences in TDI of Bama in the eyes of tourists and DMOs, however, it does not address how Bama's TDI is perceived by sojourners, who are a specific group of Bama. Is there a difference in the TDI of the health destination perceived by these two segments? Additionally, for pictures analysis, beyond the visual subjects in the images, there are many visual elements, such as colors, camera angles and view perspectives that may possibly influence viewers' feelings and emotions of certain visual content. While in the in-depth study, experiments will be designed to test whether and how these images influence the choices of travel behaviors. These will be the directions for further exploration in this study. 
Author Contributions: Conceptualization, X.H. and Y.H.; methodology, X.H.; software, X.Z.; data curation, X.Z.; validation, Q.M. and X.Z.; formal analysis, H.L. and X.Z.; investigation, Q.M. and Y.H.; writing—original draft preparation, X.H. and Q.M.; writing-review and editing, Y.H. and X.H.; visualization, X.Z.; supervision, X.H.; project administration, H.L.; funding acquisition, X.H., Y.H. and Q.M. All authors have read and agreed to the published version of the manuscript.

Funding: This research was funded by National Office for Philosophy and Social Science, grant number 21BMZ072, 21BH145 and 20BJY210, and the APC was financially funded by Maritime Silk Road and the Guangxi regional Development Institute, Program for Innovative Team of Guangxi University of Finance and Economics.

Institutional Review Board Statement: Not applicable.

Informed Consent Statement: Not applicable.

Data Availability Statement: The data presented in this study are available in the travelogues of Ctrip, Mafengwo, Qunar, Tuniu, and Lvmama, and also in the official Sina Weibo homepage and WeChat official account described within the article.

Conflicts of Interest: The authors declare no conflict of interest.

\section{References}

1. Ukpabi, D.C.; Karjaluoto, H. What drives travelers' adoption of user-generated content? A literature review. Tour. Manag. Perspect. 2018, 28, 251-273. [CrossRef]

2. $\quad$ Balshaw, M.; Kennedy, L. Urban Space and Representation; Pluto Press: London, UK, 2000; pp. 1-50.

3. Markwick, M. Postcards from Malta: Image, Consumption, Context. Ann. Tour. Res. 2001, 28, 417-438. [CrossRef]

4. Deng, N.; Li, X.R. Feeling a destination through the "right" photos: A machine learning model for DMOs' photo selection. Tour. Manag. 2018, 65, 267-278. [CrossRef]

5. Shi, P.; Ming, Q.; Han, J.; Zhang, H. Tourist perception and government publicity: A comparative study on the image dimension of tourism destinations with similar resources-A case study of Xishuangbanna prefecture and Dehong prefecture in Yunnan Province. Tour. Res. 2021, 13, 14-31.

6. Stepchenkova, S.; Zhan, F. Visual destination images of Peru: Comparative content analysis of DMO and user-generated photography. Tour. Manag. 2013, 36, 590-601. [CrossRef]

7. Foucault, M. Space, Knowledge, and Power; Pantheon Books: New York, NY, USA, 1984; pp. $239-256$.

8. Lefebvre, H.; Nicholson-Smith, D. The Production of Space; Blackwell Press: Oxford, UK, 1991; pp. 175-192.

9. Liu, D. Visual Representation and Social Construction of Place: Cultural Turn in Western Tourism Advertising Researches. Tour Sci. 2007, 21, 63-71.

10. Meng, L.; Liu, Y.; Wang, Y.; Li, X. A big-data approach for investigating destination image gap in Sanya City: When will the online and the offline goes parted? Reg. Sustain. 2021, 2, 98-108. [CrossRef]

11. Stepchenkova, S.; Kim, H.; Kirilenko, A. Cultural Differences in Pictorial Destination Images Russia through the Camera Lenses of American and Korean Tourists. J. Travel. Res. 2015, 54, 1219-1223. [CrossRef]

12. Baloglu, S.; McCleary, K.W. A model of destination image formation. Ann. Tour. Res. 1999, 26, 868-897. [CrossRef]

13. Tasci, A.; Gartner, W.C. Destination Image and Its Functional Relationships. J. Travel. Res. 2007, 45, 413-425. [CrossRef]

14. Cai, L.; Tian, M. A review of foreign destination image research in the last decade-Based on Tourism Management and Annals of Tourism Research. J. Party Sch. C.P.C. Qingdao Munic. Comm. Qingdao Adm. Inst. 2018, 6, 116-123.

15. Deng, N.; Zhong, L.; Li, H. Destination image perception based on UGC image metadata-Beijing as an example. Tour. Trib. 2018, $33,53-62$.

16. Marine-Roig; Estela; Ferrer-Rosell; Berta Measuring the gap between projected and perceived destination images of Catalonia using compositional analysis. Tour. Manag. 2018, 68, 234-249.

17. Mak Athena, H.N. Online destination image: Comparing national tourism organisation's and tourists' perspectives. Tour. Manag. 2017, 60, 280-297.

18. He, Q.; Song, S. Research on tourism development in ethnic areas and counties based on online comments-Taking Fenghuang county of Hunan Province as an example. China Tour. Rev. 2018, 4, 81-92.

19. Zhong, L. Reconstructing the perceptual structure of tourist Places-A study based on text and complex network analysis. Tour. Trib. 2015, 30, 88-95.

20. Stepchenkova, S.; Morrison, A.M. The Destination Image of Russia: From the Online Induced Perspective. Tour. Manag. 2006, 27, 943-956. [CrossRef]

21. Choi, S.; Lehto, X.Y.; Morrison, A.M. Destination image representation on the web: Content analysis of Macau travel related websites. Tour. Manag. 2007, 28, 118-129. [CrossRef]

22. Lu, L.; Zhu, S.; Liu, M. Research on evolutionary mechanism and optimization of tourism brand of Hangzhou City. Geogr. Res.-Aust. 2013, 32, 556-569. 
23. Zhang, F.; Tao, Y. Review of UGC as a data source in tourism research. Territ. Nat. Resour. Study 2019, 3, 75-77.

24. Huang, P.; Xia, Y.; Lin, R.; Li, X. Temporal and spatial characteristics of landscape imagery of Yunshuiyao ancient town based on UGC datas. J. Chin. Urban For. 2020, 18, 48-53.

25. Lu, L.; Liao, X. Research on image perception of tourism destination based on UGC data: A case study of south mount heng. Econ. Geogr. 2019, 39, 221-229.

26. Law, I.S.L.A. Tourism and online photography. Tour. Manag. 2011, 32, 725-731.

27. Deng, N.; Liu, Y.; Niu, Y.; Ji, W. Differences in travelers' perceptions of beijing destination images from different sources-A deep learning-Based analysis of Flickr images. Resour. Sci. 2019, 41, 416-429.

28. Hollenstein, L.; Purves, R. Exploring place through user-generated content: Using Flickr to describe city cores. J. Spat. Inf. Ence 2010, 1, 21-48.

29. Bai, K.; Hu, X.; Lv, Y.; Du, T. The presentation and formation of slow living localities in Lijiang old town. Acta Geogr. Sin. 2017, 72, 1104-1117.

30. Ye, Q.; Zhan, S.; Feng, G. The social construction of tourist destination image from the perspective of discourse-A case study of Hangzhou city. Resour. Dev. Mark. 2021, 37, 505-512.

31. Hitchcock, M.; Dann, G. The Language of Tourism: A Sociolinguistic Perspective. J. R. Anthropol. Inst. 1998, 4, 562. [CrossRef]

32. $\mathrm{Wu}, \mathrm{M}$; Shen, $\mathrm{H}$. Research on the relationship between visual data and destination images in the new media era. Tour. Trib. 2018, $33,5-7$.

33. Ji, S. Research on image perception of tourism destination based on UGC data: A case study of south mount Heng. Tour. Trib. 2018, 33, 5-6.

34. Stylidis, D.; Shani, A.; Belhassen, Y. Testing an integrated destination image model across residents and tourists. Tour. Manag. 2017, 58, 184-195. [CrossRef]

35. Qu, H.; Kim, L.H.; Im, H.H. A model of destination branding: Integrating the concepts of the branding and destination image. Tour. Manag. 2011, 32, 465-476. [CrossRef]

36. Yu, P. On the Emotional Image of a Tourist Destination Based on the Big-data Text Analysis. J. Zhejiang Ocean Univ. 2020, 37, 32-39.

37. Beerli, A.; Martín, J.D. Tourists' characteristics and the perceived image of tourist destinations: A quantitative analysis-A case study of Lanzarote, Spain. Tour. Manag. 2004, 25, 623-636. [CrossRef]

38. Sonmez, S.; Sirakaya, E.B. A Distorted Destination Image? The Case of Turkey. J. Travel. Res. 2002, 41, 185-196. [CrossRef]

39. Cronin, J.K. Photographic Memory: Image, Identity, and the "Imaginary Indian" in Three Recent Canadian Exhibitions. Essays Can. Writ. 2003, 80, 81-114.

40. Huang, L.; Xu, H. Bama regimen tourism-Based on the perspective of rehabilitation landscape theory. Thinking 2018, 44, 146-155.

41. Yilmaz, Y.; Yilmaz, Y.; Igen, E.T.; Ekin, Y.; Utku, B.D. Destination Image: A Comparative Study on Pre and Post Trip Image Variations. J. Hosp. Mark. Manag. 2009, 18, 461-479. [CrossRef]

42. Setiawan, C.; Meivitawanli, B.; Arrieta-Paredes, M.; Morrison, A.M.; Coca-Stefaniak, J.A. Friendly Locals and Clean Streets?Evaluating Jakarta's Destination Brand Image. Sustainability 2021, 13, 7434. [CrossRef]

43. Taberner, I.; Juncà, A. Small-Scale Sport Events as Place Branding Platforms: A Content Analysis of Osona's Projected Destination Image through Event-Related Pictures on Instagram. Sustainability 2021, 13, 12255. [CrossRef]

44. Henkel, R.; Henkel, P.; Agrusa, W.; Agrusa, J.; Tanner, J. Thailand as a tourist destination: Perceptions of international visitors and Thai residents. Asia Pac. J. Tour. Res. 2006, 11, 269-287. [CrossRef]

45. Kim, H.; Stepchenkova, S. Understanding destination personality through visitors' experience: A cross-cultural perspective. J. Destin. Mark. Manag. 2016, 6, 416-425. [CrossRef]

46. Alcaniz, E.B. Relationships among residents' image, evaluation of the stay and post-purchase behaviour. J. Vacat. Mark. 2005, 11, 291-302. [CrossRef]

47. Fuchs, M.; Pken, W.H.; Lexhagen, M. Big data analytics for knowledge generation in tourism destinations-A case from Sweden. J. Destin. Mark. Manag. 2014, 3, 198-209. [CrossRef]

48. Bai, K.; Zhou, S.; Lv, Y. The progress of social cultural geography in China in recent 10 years. Acta Geogr. Sin. 2014, 69, 1190-1206.

49. Bakos, J.Y. A strategic analysis of electronic marketplaces. Mis. Quart. 1991, 15, 295-310. [CrossRef]

50. Kozinets, R.V. E-tribalized marketing? The strategic implications of virtual communities of consumption. Eur. Manag. J. 1999, 17, 252-264. [CrossRef]

51. Huang, X.; Fan, M. A study on the representation of wellness tourism destinations based on UGC from the perspective of travelers' Power-Taking Guangxi Bama as an example. J. Guangxi Univ. Financ. Econ. 2020, 33, 110-120.

52. Matzler, K.; Ballom, F.; Hinterhuber, H.H.; Renzl, B.; Pichler, J. The asymmetric relationship between attribute-level performance and overall customer satisfaction: A reconsideration of the importance-performance analysis. Ind. Mark. Manag. 2004, 33, 271-277. [CrossRef]

53. Matzler, K.; Sauerwein, E. The Factor Structure of Customer Satisfaction: An Empirical Test of the Importance Grid and the Penalty-Reward-Contrast Analysis. Int. J. Serv. Ind. Manag. 2002, 13, 314-332. [CrossRef]

54. Schroeder, S.A.; Cornicelli, L.; Fulton, D.C.; Merchant, S.S. Explicit versus implicit motivations: Clarifying how experiences affect turkey hunter satisfaction using revised importance-performance, importance grid, and penalty-reward-contrast analyses. Hum. Dimens. Wildl. 2018, 23, 1-20. [CrossRef] 